\title{
A Reconceituação Latino-americana na Ditadura Brasileira: a renovação do Serviço Social gaúcho
}

\author{
The Latin American Reconceptualization in the \\ Brazilian Dictatorship: the renewal of the Social \\ Work in the state of Rio Grande do Sul
}

\author{
Graziela Scheffer ${ }^{a}$ \\ (D) https://orcid.org/0000-0003-1921-0879 \\ Thaisa Closs ${ }^{b}$ \\ (D) https://orcid.org/0000-0003-2602-883X \\ Inez Rocha Zacarias \\ (D) https://orcid.org/0000-0003-2325-9034
}

Resumo: $\mathrm{O}$ artigo é fruto de pesquisa sobre o Movimento de Reconceituação Latino-Americano na Escola de Serviço Social de Porto Alegre. Discute a renovação do Serviço Social gaúcho no período ditatorial, evidenciando a constituição da vertente profissional denominada de "Reformismo Reconceituador”. Aborda a caracterização dessa vertente, a qual incidiu na articulação do Movimento de Reconceituação, a partir da realização do I Seminário Latino-Americano em Porto Alegre (1965).

Palavras-chave: Fundamentos do Serviço Social. Reconceituação. Ditadura Civil-Militar. América Latina. Rio Grande do Sul.

\begin{abstract}
The article is the result of research on the Latin American Reconciliation Movement in the School of Social Work of Porto Alegre. It discusses the renewal of the Gaucho Social Work in the dictatorial period, evidencing the constitution of the professional strand denominated as "Reconceptual Reformism". It addresses the characterization of this strand, which has affected the articulation of the Reconciliation Movement, starting from the I Latin American Seminar in Porto Alegre (1965).
\end{abstract}

Keywords: Foundations of Social Work, Reconceptualization, Civil-Military Dictatorship, Latin America, Rio Grande do Sul. 


\section{Introdução}

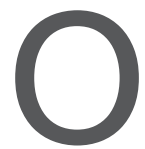

artigo apresenta os resultados da segunda etapa da pesquisa "Serviço Social, memória e Reconceituação latino-americana: antecedentes e expressões na escola de Porto Alegre”. A investigação visa analisar as particularidades da profissão no Rio Grande do Sul (RS) no processo da reconceituação latino-americana. Enfatiza a Escola ${ }^{1}$ de Serviço Social de Porto Alegre (POA), considerando que a mesma foi a organizadora do primeiro Seminário Latino-Americano, em 1965, sob coordenação de Seno Cornely. Foi a partir do grupo de professores gaúchos, em articulação com colegas uruguaios e argentinos, que se originou os encontros impulsionadores do Movimento de Reconceituação Latino-Americano, no período de 1965 a 1975.

A investigação baseou-se em entrevistas, documentos históricos e na análise quanti-qualitativa de 517 trabalhos de conclusão de curso da Escola de Porto Alegre do período de 1948-1975. Na primeira etapa da pesquisa traçamos um panorama dos antecedentes da Reconceituação na Escola de POA, concluindo que os mesmos se assentam na constituição de duas tendências de renovação profissional nos anos 1955-1965, enraizadas no processo de radicalização do trabalhismo nacionalista, de traços anti-imperialistas, nos governos municipal e estadual de Leonel Brizola. Tais tendências são: $a$ estrutural participativa, liderada por Seno Cornely, marcada pela influência do pensamento da Comissão Econômica para a América Latina (CEPAL), integrando o Desenvolvimento de Comunidade (DC), o planejamento, a política social e as técnicas de mobilização e participação social; e a pedagógica cultural, liderada pelas professoras Lucia Castillo, Zillah Totta e Notburga Reckziegel, marcada pela incidência do pensamento católico francês de Emannuel Mounier, articulando abordagens grupais e o DC com ênfase educativa, a partir das ideias de Paulo Freire e de Ernani Maria Fiori.

Ambas as tendências foram expressões da conjuntura internacional e nacional no que tange à ideologia desenvolvimentista norte-americana,

\footnotetext{
Atual Pontifícia Universidade Católica do Rio Grande do Sul.
} 
como estratégia de hegemonia capitalista na América Latina. Contraditoriamente, no movimento realizado por estas tendências, gestou-se uma consciência nacional-popular e práticas sociais de crítica e enfrentamento ao subdesenvolvimento. As expressões desse movimento, considerando o processo de constituição do Serviço Social gaúcho, convergem num projeto político de orientação socialdemocrata e humanista, na constituição de uma matriz de renovação profissional. Esta, por sua vez, foi produto da influência do nacionalismo anti-imperialista e da educação popular no Serviço Social, os quais impulsionaram a politização do exercício e da formação profissional.

A segunda etapa da pesquisa, foco do presente artigo, analisou as expressões dessas duas tendências supracitadas no Movimento da Reconceituação na Escola de Porto Alegre, assim como a sua incidência no debate latino-americano durante o regime civil-militar no Brasil. A partir dos resultados da investigação, identificamos que nos anos de 1964-68 constitui-se uma vertente profissional que propunha mudanças nas bases teórico-metodológica, ético-política e técnico-operativa do Serviço Social, possuindo caráter progressista, posto que alicerçada numa concepção macroestrutural do desenvolvimento econômico latino-americano e no exercício profissional politizador-militante. Devido a suas características, denominamos a mesma como Reformismo Reconceituador, cujas bases históricas e teórico-metodológicas serão problematizadas ao longo do artigo. Na sequência, também será discutido o processo de crise e declínio dessa vertente, que ocorre nos anos de 1969 a 1977, no quadro da intensificação da repressão dos Anos de Chumbo. Por fim, são apresentadas as conclusões da investigação sobre o Serviço Social gaúcho nesse período histórico.

\section{A processualidade histórica da renovação do Serviço Social gaúcho nas décadas de 1960-1970}

O golpe civil-militar esteve atrelado aos dilemas brasileiros do período 1961-1964, manifestados a partir da crise do modelo de dominação 
burguesa, processo em que o padrão de acumulação capitalista entrava progressivamente em contradição com as requisições democráticas, nacionais e populares (Netto, 2011). As aspirações democráticas e lutas populares possuíam elementos revolucionários e classistas que eram acompanhadas por requisições contrárias ao imperialismo norte-americano e ao latifúndio, apontando para uma mudança no padrão de desenvolvimento econômico e na democratização da sociedade e do Estado (Netto, 2011). Portanto, a crise da forma da dominação burguesa integra os antecedentes democratizantes do início da década 1960 e as disputas regionais no país, o que se expressa na atuação de Leonel Brizola, ex-governador do RS.

Entre os anos de 1961-1962, Brizola atuou na articulação da Frente de Libertação Nacional (FNL), juntamente com lideranças que participaram do movimento da Legalidade ${ }^{2}$. Essa frente defendia a nacionalização das companhias estrangeiras, a regulamentação da Lei de Remessa de Lucros, a Reforma Agrária, condenava tanto a intromissão norte-americana ou soviética na política interna ou externa brasileira (Kornis, 2010). Como expressão da conjuntura nacional, as eleições governamentais no RS, em 1962, condensaram a forte oposição aos segmentos trabalhistas, com o apoio das chamadas "classes produtoras" e da mídia local. As crescentes críticas ao presidente João Goulart (Jango) e a gestão estadual de Brizola, acentuadas por um baixo crescimento da economia gaúcha, forneceram as bases de um cenário político favorável ao posterior golpe de 1964, que contou com a participação atividade do então governador do RS, Ildo Meneghetti. (Padrós, Barbosa, Lopez, Fernandes et al., 2014).

O posicionamento político de Brizola sobre essa conjuntura enfatizava a necessidade da arregimentação de forças progressistas na sustentação às Reformas de Base, o que se expressou na constituição do chamado Grupo dos Onze Companheiros, em outubro de 1963, por Brizola. Esse movimento teve significativa incidência no RS, e além da defesa das Reformas, preconizava

2 A tentativa de golpe contra João Goulart foi barrada em 1961 pela Campanha da Legalidade, a partir de resistência organizada regional e nacionalmente pelo então governador do RS, Leonel Brizola. 
a "libertação do Brasil da espoliação internacional" (Lamarão, 2010). Destaca-se a colaboração de Hebert José de Souza - conhecido como "Betinho", liderança da Ação Popular (AP) — na coordenação nacional dos Grupos dos Onze (Montalvão, 2010).

Betinho foi um dos fundadores e o primeiro coordenador nacional da AP, organização política formada em 1962 por participantes oriundos da Juventude Universitária Católica (JUC), que aprofundaram sua militância política no âmbito da esquerda. Como aponta Pires (2015), foi o próprio Betinho que protagonizou a articulação que daria início às atividades da AP no RS, contando com o apoio de Maria Josefina Becker, na época estudante de Serviço Social da Escola de Porto Alegre.

Nesse período destaca-se também a inserção de militantes da AP nas ações governamentais através de cargos públicos e também na constituição de movimentos de cultura popular nas comunidades de Porto Alegre (Dias, 2011), cuja experiência de atuação de estudantes de Serviço Social da Escola de Porto Alegre encontra-se registrada em trabalhos de conclusão de curso datados de 1963 e 1964. Tais ações contavam com o apoio de Ernani Maria Fiori, filósofo integrante da AP e docente da UFRGS, que protagonizou a criação do Instituto de Cultura Popular no RS (ICP-RS) no ano de 1963. A partir desse período Fiori fortalece sua interlocução com o educador Paulo Freire, a qual se estenderá ao exílio de ambos no Chile.

Além da polarização de forças políticas no país, entendemos que a crise da forma de dominação burguesa no Brasil se insere no quadro mais amplo da Guerra Fria na América Latina, principalmente após a vitória do socialismo cubano no continente. Nesse quadro, Brizola passou a assumir uma orientação política de caráter desenvolvimentista e anti-imperialista, a qual acirrou a oposição dos setores conversadores a sua liderança política, tanto no âmbito nacional como regionalmente.

O golpe desencadeado em 31 de abril de 1964 foi alvo de resistências no Rio Grande do Sul, a Cadeia da Legalidade foi reativada, convocando o povo à resistência. Jango chegou a Porto Alegre em 2 de abril de 1964, reuniu-se com Brizola e militares. Avaliando que não teria o apoio necessário para resistir ao golpe, recusou-se a distribuir armas para a população que estava 
disposta ao combate. No mesmo dia partiu no avião presidencial para o exílio em Montevidéu. $\mathrm{O}$ golpe contra a incipiente democracia brasileira consolidou-se, protagonizado pelas classes dominantes brasileiras sob influência dos interesses do capital monopolista internacional e com o incentivo dos órgãos governamentais norte-americanos.

No que se refere à análise da ditadura civil-militar no RS, em sua dinâmica de resistência e repressão, partimos da premissa de que a particularidade que a mesma assume regionalmente decorre da forte influência do projeto desenvolvimentista-nacionalista, sob a liderança de Brizola nas disputas políticas regionais e nacionais, com relevante participação dos setores da esquerda católica (AP). Além disso, é necessário considerar a localização geográfica fronteiriça do RS com o Uruguai e a Argentina, que influiu tanto na cooperação entre os regimes militares, bem como nas ações de resistência. Esses aspectos se evidenciam nos dois momentos distintos da ditadura: o da Operação Limpeza (1964 a 1968) e os Anos de Chumbo (1968 a 1978), subsidiando a análise histórica do Serviço Social gaúcho no período em tela.

\subsection{Operação Limpeza e articulação latino-americana: a gênese do Reformismo Reconceituador na Escola de Porto Alegre (1965-1968)}

A operação limpeza consistiu na primeira fase repressiva amparada no Ato Institucional n. 1, que levou a derrubada de Jango da presidência e a inserção das Forças Armadas no Poder. Nesse período houve a perseguição político-ideológica que levou a demissão de funcionários públicos e ao exílio dos grupos de oposição ao regime ditatorial no Uruguai.

A resistência ao golpe organizou o Esquema Montevideo visando compor as forças de esquerda de Brizola e Jango no exílio uruguaio. Dentre as ações de resistência que caracterizaram esse primeiro ciclo de resistência-repressão, destacam-se: a tentativa de levante nos quartéis de Porto Alegre; a Guerrilha de Três Passos na fronteira com Uruguai, em 1965; a Guerrilha 
de Caparaó, na divisa dos estados de Minas Gerais e Espírito Santo, nos anos de 1966 a 1967.

Com o desencadeamento da Operação Limpeza, o grupo pertencente à tendência pedagógica cultural foi imediatamente atingido, devido a sua estreita ligação com a AP e com as ações de educação popular. A professora Notburga Reckziegel foi afastada do cargo de Diretora da Escola Porto Alegre. Zilah Totta, também docente da Escola de Porto Alegre, foi demitida do cargo diretivo da Secretaria Estadual de Educação. Maria Becker, assistente social vinculada a AP e que desenvolvia o trabalho de educação popular na época, recorda que o novo secretário, Paulo Amorim, se reuniu com o grupo da subdivisão de cultura popular em maio de 1964 e disse-lhes que seria necessário dar menos destaque à ênfase da politização, tendo em vista possíveis ações de repressão (Becker, 2018). O ICP-RS, criado com a ajuda de professores da Escola de Serviço Social de Porto Alegre, teve suas atividades encerradas após 3 meses. Conforme depoimento de Lúcia Castillo (Bulla, 1992), após o golpe militar, esse grupo teve que se dispersar, inclusive incinerando materiais e documentos que estavam sendo utilizados nessa inédita e curta iniciativa.

O professor de filosofia Ernani Fiori, que atuava no ICP-RS, foi expulso da UFRGS, em 1964, devido a sua atuação política na defesa de uma reforma democrática da universidade. A sua demissão acarretou numa reação imediata de alunos e professores que se solidarizaram com o professor, que se viu obrigado, após a esse episódio, a se exilar no Chile juntamente com Paulo Freire.

Em $1^{\circ}$ de abril de 1964, foi realizada uma assembleia extraordinária pelo Sindicato dos Assistentes Sociais de Porto Alegre, na qual foi produzido um documento nomeado "Manifesto ao Povo", assinado pelos representantes do Sindicato, do Conselho Regional de Assistentes Sociais e pela Direção da Escola de Serviço Social de Porto Alegre. O manifesto, além de declarar oposição ao quadro político ditatorial que se configurava no Brasil, defendia as Reformas de Base. A tendência estrutural-participava era formada por segmentos do Sindicato de Assistentes Sociais, sendo Seno Cornely um dos fundadores dessa entidade, criada em 1958. Parte dos assistentes 
sociais sindicalistas encontravam-se na Secretaria Estadual de Trabalho e Habitação, o desmonte do trabalho de Seminários de Comunidade desenvolvido por esse grupo foi mais gradual (Krug, 2018). A operação limpeza atingiu essa Secretaria em 1967 através de demissões de profissionais do seu quadro e da interrupção do convênio com a Escola de Serviço Social da PUCRS, momento em que é criada a Fundação de Bem-Estar do Menor (Cornely, 2008).

Concomitantemente aos "ataques", ocorreu a reorganização das forças da resistência que, nessa ocasião, alcançaram um novo patamar com o Seminário de 1965, sedimentando-se numa perspectiva latino-americana articulada com a denominada “Geração 65”, formada principalmente por profissionais brasileiros, uruguaios e argentinos. Netto (2011, p. 141) aponta que foi no marco da ditadura burguesa, com o avanço da tecnocracia e da laicização, que se impulsionou o processo de renovação da profissão no Brasil, definida como "uma resposta construída pelos assistentes sociais na rede de relações que se entrelaçam na interação profissionalidade-sociedade". Contudo, o legado renovador da politização da profissão entre os anos 1960-1964 foi atingido parcialmente, pois houve uma assimetria temporal da intervenção autocrático-burguesa, que atacou de imediato os suportes sociopolíticos das tendências profissionais críticas e avançadas, mas só um lustro depois conseguiu eliminar a ambiência teórico-cultural que as mobilizava (Netto, 2011).

Apesar do golpe de 1964, a erosão do Serviço Social Tradicional vem à tona em 1965, na cidade de Porto Alegre, a partir do "I Seminário Regional de Serviço Social frente às mudanças na América Latina”, que tensionou a legitimidade das orientações norte-americanas na formação profissional da época. Sobre articulação gaúcha no Conesul, destaca-se que:

É este movimento, localizável praticamente em todos os países ao Sul do Rio Grande, permitiu uma espécie de grande união profissional que abre a via a uma renovação do Serviço Social. Ela é o ponto de partida para o processo que se esboça em 1965 e que, genericamente, tem o objetivo expresso de adequar a profissão às demandas de mudanças sociais registradas ou desejadas no 
marco constitucional e que sensibilizam o Serviço Social pelos condutos e sujeitos que, internacionalmente (...) forçavam e parametravam as alterações profissionais. (Netto, 2011, p. 146-147)

O evento de 1965 deu origem ao Movimento Reconceituação Latino-Americano por meio da organização de seminários em diferentes países até o ano de 1975. Visava a constituição de uma frente profissional latino-americana permeada

"pela ideologia anti-imperialista (...) que se apoiava no explícito reconhecimento da urgência de fundar uma unidade profissional que respondesse às problemáticas comuns da América Latina - unidade construída autonomamente e sem tutelas imperiais" (Netto, 2011, p. 146).

O debate da unidade profissional foi permeado pelas ideias desenvolvimentistas da CEPAL a partir da concepção de subdesenvolvimento econômico e cultural dos países latino-americanos, como particularidade histórica e estrutural do capitalismo periférico. O Estado Nacional deveria ser o indutor do desenvolvimento e da "modernização" por meio das mudanças das estruturas sociais, fortalecendo a economia "interna" e as políticas sociais.

É nesse quadro, na dinâmica contraditória dos processos de repressão-resistência entre os 1964 a 1968, que situa-se o processo de criação e expansão da vertente "Reformismo Reconceituador". A mesma representou, na Escola de Porto Alegre, uma aproximação das tendências renovadoras do pré-1964, unificadas em torno do trabalhismo e da ideologia nacional-desenvolvimentista da CEPAL, articulando traços anti-imperialistas com o pensamento da esquerda cristã francesa. $O$ quadro a seguir sistematiza os elementos centrais das matrizes teórico-políticas dessa vertente e suas expressões na Escola.

Conforme a investigação realizada, infere-se que a nova vertente na Escola se organizava a partir dos seguintes princípios: a) defesa da unidade latino-americana numa perspectiva anti-imperialista e nacionalista; 
Quadro 1. Matrizes teórico-políticas do Reformismo Reconceituador

\begin{tabular}{|c|c|c|c|}
\hline MATRIZ & SOCIEDADE & AMÉRICA LATINA & $\begin{array}{l}\text { EXPRESSÃO NA } \\
\text { ESCOLA DE POA }\end{array}$ \\
\hline $\begin{array}{c}\text { Trabalhismo - PTB. } \\
\text { Alberto Pasqualini - } \\
\text { Bases e sugestão para } \\
\text { uma política social } \\
\text { (1948). }\end{array}$ & $\begin{array}{l}\text { Social-democracia. } \\
\text { Capitalismo solidarista } \\
\text { com regulação estatal } \\
\text { e expansão econômica } \\
\text { subordinada aos } \\
\text { interesses coletivos. }\end{array}$ & $\begin{array}{l}\text { Anti-imperialismo } \\
\text { norte-americano. } \\
\text { Defesa de uma } \\
\text { cidadania } \\
\text { latino-americana. }\end{array}$ & $\begin{array}{c}\text { Curso de } \\
\text { Administração em } \\
\text { Serviço Social e } \\
\text { Política Social (1957). }\end{array}$ \\
\hline $\begin{array}{l}\text { Estruturalismo } \\
\text { Latino-Americano. } \\
\text { Celso Furtado } \\
\text { - Entre o } \\
\text { inconformismo e o } \\
\text { reformismo (1992). }\end{array}$ & $\begin{array}{l}\text { Estado Nacional } \\
\text { Planificado, } \\
\text { modernizador da } \\
\text { economia, executor } \\
\text { do desenvolvimento. } \\
\text { Industrialização } \\
\text { substitutiva de } \\
\text { importações. }\end{array}$ & $\begin{array}{c}\text { Crítica a economia } \\
\text { desigual e periférica } \\
\text { centrada no } \\
\text { capitalismo central, } \\
\text { ao atraso tecnológico } \\
\text { e a deterioração das } \\
\text { trocas de produtos. }\end{array}$ & $\begin{array}{l}\text { Seminário de } \\
1965 \text { (todos os } \\
\text { palestrantes). }\end{array}$ \\
\hline $\begin{array}{c}\text { Desenvolvimento } \\
\text { Humanista. Padre } \\
\text { Lebret } \\
\text { Suicídio ou } \\
\text { sobrevivência do } \\
\text { Ocidente (1960). }\end{array}$ & $\begin{array}{l}\text { Economia humanista. } \\
\text { O capitalismo passa por } \\
\text { crises cíclicas, violentas } \\
\text { e por tensão de classes. } \\
\text { O conflito tornou- } \\
\text { se universal pela } \\
\text { expansão imperialista } \\
\text { norte-americana. }\end{array}$ & $\begin{array}{l}\text { Anti-imperialismo } \\
\text { norte-americano. } \\
\text { Ênfase no } \\
\text { desenvolvimento } \\
\text { humanista e na } \\
\text { organização de } \\
\text { apoio aos países } \\
\text { subdesenvolvidos. } \\
\text { Vanguarda do } \\
\text { catolicismo social. }\end{array}$ & $\begin{array}{l}\text { Seno Cornely foi } \\
\text { pesquisador da } \\
\text { equipe da Economia } \\
\text { Humana. } \\
\text { Disciplina de } \\
\text { pesquisa. }\end{array}$ \\
\hline $\begin{array}{c}\text { Socialismo } \\
\text { personalista. } \\
\text { Emmanuel Mounier } \\
\text { - O personalismo } \\
\text { (1960). }\end{array}$ & $\begin{array}{l}\text { Socialismo personalista } \\
\text { visa a substituição } \\
\text { da economia fundada } \\
\text { no lucro para uma } \\
\text { economia das pessoas, } \\
\text { do primado do trabalho } \\
\text { sobre o capital. }\end{array}$ & $\begin{array}{c}\text { Crítica } \\
\text { anticapitalista. } \\
\text { A democracia } \\
\text { política deve se } \\
\text { sobrepor sobre } \\
\text { à democracia } \\
\text { econômica e às } \\
\text { estruturas de } \\
\text { produção. }\end{array}$ & $\begin{array}{l}\text { Influenciou Ernani } \\
\text { Fiori, Paulo Freire } \\
\text { e a Ação Popular. } \\
\text { Disciplina de Ética. }\end{array}$ \\
\hline
\end{tabular}

Fonte: Sistematização das autoras.

b) compreensão das políticas sociais com via de humanização das estruturas capitalistas; c) ênfase para a participação social como fundamento da democracia e da cidadania; d) ênfase na organização sindical e na luta corporativa por melhorias sociais (salários, reconhecimento estatal, serviços públicos, entre outros aspectos); e) defesa da formação profissional alinhada 
às particularidades da realidade latino-americana; f) defesa de um perfil profissional do assistente social com capacidade teórica, técnica e política para a gestão e o planejamento das políticas sociais, a fim de induzir a mudanças sociais.

No Seminário de 1965, que evidencia a cultura profissional na Escola de Porto Alegre e expressa as forças de resistências existentes no RS, os palestrantes brasileiros apresentaram em comum conceitos da CEPAL no entendimento do desenvolvimento social na América Latina. Entre esses, Lucia Castillo, na sua fala de encerramento do Seminário, destaca que o "Serviço Social representa uma forma de política social e controle social" (...) sua ação prática é tributária do contexto econômico e sociocultural dentro qual se insere" (Castillo, 1965, p. 4), pois a profissão "nasce dentro do sistema capitalista e como forma de correção das disfunções sociais criadas pelo sistema. Não como única forma, mas como uma delas" (Castillo, 1965, p. 10).

A partir desse evento houve a realização dos demais seminários regionais latino-americanos, destacando-se, nessa primeira fase do Reformismo Reconceituador, a participação dos professores gaúchos nos seguintes seminários: II Seminário (1996-Uruguai) em que os debates centram-se numa visão macroestrutural do Serviço Social, momento em que Seno Cornely palestrou sobre o "Papel del Servicio Social en el desarrollo"; e o III Seminário (1967-Argentina), cuja temática central foi a educação e os grupos, contando com a presença de Seno Cornely e com a palestra proferida por Notburga Reckziegel.

Em âmbito regional, o ciclo repressivo da operação limpeza atingiu os segmentos que protagonizavam a tendência do "Reformismo Reconceituador”, processo intensificado posteriormente com a reforma educacional efetivada pela ditadura civil-militar. Essa reforma, além de impor uma repressão interna nas instituições de ensino superior, controlando todo e qualquer tipo de manifestação contrária ao regime ditatorial, instituiu uma lógica de ensino ajustada às tendências tecnicistas e modernizadoras defendidas pelo regime ditatorial. Esse cerco repressivo sob a atuação dos segmentos do Reformismo Reconceituador acarretou numa diminuição do debate anticapitalista de Mounier no âmbito da formação profissional na Escola de 
Porto Alegre, mantendo no seu interior as teses da CEPAL, que passam a ser articuladas ao pensamento cristão-desenvolvimentista de Lebret e ao pensamento educacional das primeiras elaborações de Paulo Freire.

Netto (2011) aponta que, além da renovação latino-americana, constituíram-se três vertentes renovadoras no país, quais sejam: a modernização conservadora, a reatualização do conservadorismo e a intenção de ruptura. A primeira vertente foi impulsionada pelo CBCISS, especialmente com o Documento de Araxá (1967) e Documento de Teresópolis (1972), cuja orientação teórica seguia o estrutural-funcionalismo, tendo como expoente José Lucena Dantas. Suas propostas incentivavam a adequação da profissão à tecnocracia ditatorial com ênfase no arsenal técnico-instrumental, no planejamento e na administração alinhada ao capitalismo imperialista. Já a segunda vertente emerge na metade dos anos 1970, com base na Fenomenologia e no Existencialismo cristãos. Sua constituição se deu em escola carioca (PUC-RJ), cuja principal docente foi Anna Augusta Almeida, a qual buscou resgatar a dimensão psicologista e o humanismo abstrato cristão. A terceira vertente constitui-se no início da década de 1970, inspirada nas teorias marxistas e freirianas, visando romper com a herança conservadora da profissão. Sua origem é a faculdade mineira de Serviço Social de Belo Horizonte (BH), sob a liderança de Leila Lima Santos, com a proposta conhecida como "Método de BH". No tópico seguinte apresentamos uma análise comparativa entre o Reformismo Reconceituador e a Modernização Conservadora, no contexto dos Anos de Chumbo.

\subsection{Os Anos de Chumbo: a reação da Modernização Conservadora ao Reformismo Reconceituador (1968-1975)}

Os Anos de Chumbo representaram, no curso da ditadura civil-militar no Brasil, o aprofundamento da violência pautada no Ato Institucional n. 5 (AI-5) e na Operação Condor, generalizando o terrorismo de Estado sustentado na Doutrina da Segurança Nacional. Em 1968, no Brasil, tivemos grandes manifestações políticas de estudantes e intelectuais contra o regime ditatorial, buscando uma saída "pacífica" da ditadura, contudo, o resultado 
foi o aumento da repressão. Em 1969 abre-se uma nova etapa de resistência-repressão, momento em que se generaliza a violência militar, ataca-se os exilados políticos nos países vizinhos e se expande a resistência por meio das guerrilhas urbanas. Os historiadores consideram que a Operação Condor teve início em 1970, antes mesmo da assinatura oficial do documento em 1975. Apesar do governo brasileiro não assumir sua participação na operação, os estudiosos o consideram como o mentor da mesma.

Na época, a resistência criou o Esquema da Travessia, no qual Porto Alegre foi sede estratégica, devido a fronteira com a Argentina e o Uruguai. Em 1968, Carlos Marighela procurou Frei Betto para organizar a saída dos militantes para o exílio:

Ele soubera que eu estava de mudança para o Rio Grande do Sul e queria que eu aceitasse acompanhar, em Porto Alegre, a passagem de refugiados políticos que se destinavam a entrar no Uruguai para, em seguida, viajar a Europa (...). Aceitei o pedido, ciente de que ele se adequava à tradição da Igreja de auxílio a refugiados políticos. (Betto, 1987, p. 6).

No que tange aos impactos da ditadura civil-miliar na Escola de Porto Alegre, as consequências dessa virada política conservadora e repressiva ainda são pouco conhecidas em seus detalhes. Após a vitória do movimento golpista, a repressão no RS logo se fez sentir sobre aqueles que tinham atuação política no campo da esquerda no período anterior de 1961-1964. A partir da análise dos inquéritos do período, verifica-se que 61 assistentes sociais e 24 estudantes foram processados no período ditatorial, sendo que dentre a listagem identifica-se Jorge Gilberto Krug, ex-aluno da Escola de Porto Alegre (Stampa, 2017). Registra-se também a prisão do então professor da Escola de Serviço Social de Pelotas, Alceu Salamoni, integrante da AP (Silveira, 2010), bem como o exílio de Eva Terezinha com seu companheiro Vicente Faleiros no Chile, a qual participara das ações de educação popular nos anos de 1963-1964 em Porto Alegre, tendo também pertencido a AP (Becker, 2018).

Dentre as tendências profissionais nesse período, é importante demarcar a diferenciação entre a vertente denominada de Modernização Conservadora (Netto, 2011) e o Reformismo Reconceituador. Embora ambas 
possuíssem como traço comum a ênfase no exercício profissional modernizador, pautado pelo planejamento e pela gestão das políticas sociais, a fronteira de diferenciação entre ambas reside na concepção de participação, no seu arcabouço teórico e na sua direção ideopolítica, apresentando diferentes nuances sobre o perfil e o exercício profissional. Esses aspectos se encontram sistematizados no quadro a seguir, a partir dos resultados obtidos na pesquisa histórica.

Quadro 2. Diferenciação entre a Modernização Conservadora e o Reformismo Reconceituador

\begin{tabular}{|c|c|c|}
\hline DIMENSÕES & $\begin{array}{l}\text { MODERNIZAÇÃO } \\
\text { CONSERVADORA }\end{array}$ & $\begin{array}{c}\text { REFORMISMO } \\
\text { RECONCEITUADOR }\end{array}$ \\
\hline Arcabouço teórico & $\begin{array}{c}\text { Estruturalismo funcionalista } \\
\text { norte-americano }\end{array}$ & $\begin{array}{l}\text { Estruturalismo latino- } \\
\text { americano (CEPAL). }\end{array}$ \\
\hline Direção ideopolítica & $\begin{array}{c}\text { Supostamente neutro } \\
\text { Unidade técnico-operativa }\end{array}$ & $\begin{array}{l}\text { Social-democrata } \\
\text { anti-imperialista } \\
\text { Unidade política } \\
\text { latino-americana. }\end{array}$ \\
\hline Exercício profissional & $\begin{array}{l}\text { Planejamento tecnocrático, } \\
\text { ênfase na metodologia } \\
\text { profissional e na política } \\
\text { social pautada em reformas } \\
\text { sociais "pelo alto". }\end{array}$ & $\begin{array}{l}\text { Planejamento participativo, } \\
\text { ênfase na gestão democrática } \\
\text { e na política social pautada } \\
\text { em reformas sociais com } \\
\text { participação social. }\end{array}$ \\
\hline Perfil profissional & $\begin{array}{l}\text { Gestor burocrático e } \\
\text { agente técnico }\end{array}$ & $\begin{array}{l}\text { Gestor democrático e } \\
\text { agente da mudança. }\end{array}$ \\
\hline
\end{tabular}

Fonte: Elaboração das autoras.

A segunda fase, abrangendo o período de 1969 a 1977, abarca a crise e declínio do Reformismo Reconceituador, na conjuntura dos Anos de Chumbo, sob a vigência do AI-5. Neste momento, essa vertente sofre um processo de isolamento, fruto desse contexto repressivo e da intensificação da influência norte-americana, combinada ao avanço da vertente da modernização conservadora, manifestada pelos documentos de Araxá e Teresópolis. Os marcos dessa crise se deram a partir da demissão dos profissionais vinculados a Secretaria de Trabalho e Habitação (1967), na realização do Seminário da OEA em Porto Alegre (1969) e na divulgação internacional dos documentos do 
CBCISS. Da mesma forma, também incidem no processo de crise, as críticas direcionadas ao Seminário Latino-americano realizado em 1972 na capital gaúcha, culminando posteriormente no fim do Movimento Reconceituador em 1975 no quadro das ditaduras na América Latina.

Nesse mesmo período de 1965 a 1975 identificou-se, através da revisão dos 288 trabalhos de curso da Escola de Porto Alegre dessa década, uma mudança no perfil das experiências profissionais em relação à década anterior. As mesmas passam a se concentrar predominantemente em abordagens grupais (105 de 288), seguidas das abordagens de DC e grupo-DC (63 de 288), permanecendo reduzido o universo de experiências de Serviço Social de Caso (41 de 288), ao passo que ampliam-se outras abordagens e temáticas (34 de 288). Uma hipótese é o possível deslocamento da vertente do Reformismo Reconceituador, especialmente na sua fase de declínio, para o âmbito do Serviço Social de grupo em diferentes espaços de atuação, mas já destituído parcialmente do seu caráter popular e educativo. Nessa fase, o Serviço Social de grupo passa a enfatizar o trabalho no âmbito das instituições. No que tange às abordagens de DC e grupo-DC, evidencia-se uma concentração das experiências (14 de 63) em ações vinculadas a Secretaria de Trabalho e Ação Social³, evidenciando um lócus de incidência da referida vertente. Nesse decênio há a emergência de unidades da Legião Brasileira de Assistência como espaço de atuação de DC e grupo-DC (11 de 63), seguidas pela continuidade das experiências no Serviço Social da Indústria (10 de 63). No que se refere às outras temáticas, em sua maioria abarcam pesquisas sobre a realidade da população usuária, das políticas setoriais e da atuação do Serviço Social (17 de 34).

É importante destacar o ano de 1969, no qual realizou-se no RS o Seminário da OEA sobre DC, momento em que a Escola inicia o processo de reforma curricular. A partir dessa reforma, os Documentos dos Seminários de Araxá e de Teresópolis tornaram-se as principais referências da formação profissional em Porto Alegre, desconsiderando as propostas do grupo vinculado ao Reformismo Reconceituador. No mesmo ano de 1969 ocorre o IV Seminário Latino-Americano no Chile e publica-se na Revista Hoy en el Trabajo Social o artigo de Paulo Freire intitulado "Rol del Trabajo Social

\footnotetext{
A partir da reestruturação da Secretaria de Trabalho e Habitação.
} 
en el Proceso de Cambio". Consideramos que o evento ampliou a influência de Paulo Freire no Serviço Social latino-americano. No ano de 1970 ocorre o V Seminário na Bolívia, no qual entre os conferencistas tivemos a presença de Seno Cornely palestrando sobre o tema "Un nuevo modelo de agencia”. Em 1971 ocorre o "Primer Seminario de Reconceptualización del Servicio Social”, realizado na Argentina. Entre os palestrantes brasileiros registra-se Vicente Faleiros, abordando a "Metodologia cientifica em Servicio Social" e Seno Cornely discutindo o tema "Planificación Social - Tecnicas de Proyectos".

Em 1972 é realizado o VI Seminário, novamente em Porto Alegre, ocorrendo em um dos mais repressivos anos da ditadura brasileira, considerando a perseguição dos militares ao segmento de esquerda, as fugas para o exílio e as guerrilhas urbanas. Como relata Cornely (1979), o seminário assumiu um caráter "pragmático" devido ao contexto repressivo, se atendo a aspectos metodológicos e para o debate da relação dialética entre teoria e prática. Também relata que o Reitor Irmão José Otão (PUCRS), teve que pessoalmente se responsabilizar pelo seminário, pois havia ameaças diretas das chamadas forças de segurança. O seminário não agradou grande parte dos colegas latino-americanos, tendo sido criticado pelo seu caráter asséptico e metodológico. Em 1976 ocorre o VII Seminário Latino-americano, na cidade de Lima (Peru).

\title{
Considerações finais
}

\begin{abstract}
Novas ilhas, novos rios, novos vulcões fazem do nosso continente, uma nova geografia. Queremos nova agricultura, outras forças juvenis, uma sociedade mais pura. Novos protagonistas da história, que está nascendo, e que temos o dever de construir. Quem pode estar contra a vida? Celebremos a chegada de Leonel Brizola, no cenário da América Latina, como uma deslumbrante encarnação de nossas esperanças.
\end{abstract}

Pablo Neruda

Como ilustra o poema, o Serviço Social gaúcho também chegou ao cenário da América Latina, a partir da organização do I Seminário em Porto Alegre, trazendo esperanças de novos tempos para a profissão, como parte 
do espírito renovador que alimentou o Movimento de Reconceituação. A partir dos resultados da pesquisa, verifica-se a relevância da Escola de Porto Alegre no impulso e desenvolvimento dos seminários latino-americanos, processo histórico imerso numa dialética de repressão-resistência cuja síntese se expressa na constituição da vertente do Reformismo Reconceituador. 0 protagonismo da Escola na organização do I Seminário Latino-Americano relaciona-se com os processos de renovação da profissão no quadro da conjuntura sócio-política regional na transição dos anos 1950 a 1960, sob a influência do trabalhismo nacionalista de traços anti-imperialistas nos governos municipal e estadual de Leonel Brizola, juntamente com a gestação de uma consciência nacional-popular e práticas sociais de crítica e enfrentamento ao subdesenvolvimento no bojo da ideologia desenvolvimentista.

A repressão iniciada após o golpe de 1964, ao mesmo tempo que restringiu as experiências renovadoras no âmbito dos organismos estatais, impulsionou a aglutinação dos docentes da Escola em torno na ideologia nacional-desenvolvimentista, dando vazão à criação e à expansão da vertente do Reformismo Reconceituador nos anos de 1965-1968.

No contexto da Operação Limpeza da ditadura civil-militar, verifica-se que os impactos iniciais da repressão incidem no fechamento do ICP-RS e na reorganização da estrutura da Secretaria de Trabalho e Habitação, restringindo as experiências de DC articuladas via estágios na Escola de Porto Alegre, embora ainda se verifique nos trabalhos de conclusão de curso desse período ações interventivas alinhadas com o Reformismo Reconceituador. No âmbito do currículo, verifica-se a permanência do debate das concepções da CEPAL, de Paulo Freire e de Emannuel Mounier, com um crescente direcionamento para a discussão da unidade latino-americana. Esse processo está relacionado com a realização do I Seminário latino-americano em 1965 e com a participação de docentes da Escola nos II e III Seminários no Uruguai e na Argentina.

Nos anos de 1969 a 1975 ocorre a crise e declínio dessa vertente, na conjuntura dos Anos de Chumbo. O debate em torno do pensamento da CEPAL e de Paulo Freire é suprimido na formação profissional da Escola, ocorrendo a influência crescente da vertente da modernização conservadora, 
expressa nos documentos de Araxá e Teresópolis do CBCISS, cujas características foram abordadas no quadro 1 . Com o avanço da repressão e com a mudança curricular implementada em 1969, impulsionada pela política educacional da ditadura, a vertente do Reformismo Reconceituador tem seu espaço de atuação restringido localmente, passando a incidir prioritariamente nos debates dos Seminários latino-americanos realizados a partir de então, especialmente através da participação de Seno Cornely nos mesmos.

\section{Referências}

ANDER-EGG, E. Lectura crítica del Documento de Teresopolis. In: Revista Hoy en Trabajo Social. Buenos Aires: Editorial ECRO, 1972.

BETTO, F. Batismo de Sangue. Rio de Janeiro: Bertrand, 1987.

BULLA, L. C. Serviço Social, Educação e Práxis: tendências históricas e metodológicas. Porto Alegre: UFRGS, 1992.

CASTILLO, L. Anais do I Seminário de Reconceituação Latino-Americano. Porto Alegre: PUCRS, 1965.

CORNELY, S. Entrevista a Seno Cornely. Revista Acción Crítica. Lima: ALAETS, 1979.

. Crônicas de uma história recente: Alguns avanços que deram maior visibilidade ao serviço social gaúcho, especialmente à Faculdade de Serviço Social. Textos e Contextos. Porto Alegre: PUCRS, 2008.

DANTAS, Lucena. La Reforma de enseñanza y de la profesión de Servicio Social. In: Selecciones de Servicio Social. n. 11, Buenos Aires, setembro de 1970.

DIAS, C. M. A Ação Popular no Rio Grande do Sul: 1962-1972. Passo Fundo: UPF, 2011.

ECRO. Esos intricados problemas de la reconceptualización. In: Revista Hoy en el Trabajo Social n. 21. Buenos Aires: Editorial ECRO. 1971.

. Crónica del $5^{\circ}$ Seminario Regional Latinoamericano de Servicio Social. In: Revista Hoy en el Trabajo Social. Buenos Aires: Editorial ECRO, 1970.

KORNIS, M. Frente de Libertação Nacional. Dicionário Histórico-Biográfico Brasileiro Pós-1930. Rio de Janeiro: CPDOC, 2010.

LAMARÃO, S. Grupo dos Onze. Dicionário Histórico-Biográfico Brasileiro - Pós-1930. Rio de Janeiro: CPDOC, 2010.

MONTALVÃO, S. Betinho. Dicionário Histórico-Biográfico Brasileiro - Pós-1930. Rio de Janeiro: CPDOC, 2010. 
NETTO, J. P. Ditadura e Serviço Social: uma análise do Serviço Social no Brasil pós-1964. São Paulo: Cortez, 2011.

Pequena história da ditadura brasileira (1964-1985). São Paulo: Cortez, 2014.

PADRÓS, E. S.; BARBOSA, V. B.; LOPEZ, V. A.; FERNANDES, A. S. Ditadura de Segurança Nacional no Rio Grande do Sul: história e memória. v. 1. 3. ed. Porto Alegre: Assembleia Legislativa, 2014.

PIRES, T. V. Fazendo revolução a vida inteira: memória e resistência entre os militantes da Ação Popular no Rio Grande do Sul. São Leopoldo: Unisinos, 2015.

RIO GRANDE DO SUL. Secretaria de Trabalho e Habitação. I Seminário Regional de Serviço Social frente às mudanças na América Latina. Porto Alegre, 1965.

SILVEIRA, M. B. A. da. A Resistência ao Golpe e Ditadura Militar em Pelotas: reflexões sobre uma cidade do interior e próxima à fronteira. Anais do X Encontro Nacional de História. Santa Maria, 2010.

STAMPA, I. Assistentes sociais e estudantes de Serviço Social na luta contra o regime ditatorial no Brasil. Relatório de Pesquisa, Rio de Janeiro: PUCRIO, 2017.

\section{Sobre as autoras}

Graziela Scheffer - Doutora em Serviço Social.

E-mail: graziela.uerj@gmail.com

Thaisa Closs - Assistente social. Doutora em Serviço Social.

E-mail: thaisacloss@hotmail.com

InEz Rocha ZACARIAS - Doutora em Serviço Social. Docente do Departamento de Serviço Social.

E-mail: inez.zacarias@ufsc.br 